\section{P224 HOW DO THE TIMINGS OF REACTIONS DURING SPECIFIC INHALATION CHALLENGE RELATE TO REAL WORLD EXPOSURES IN OCCUPATIONAL ASTHMA?}

VC Moore, PS Burge, AS Robertson, GI Walters. Birmingham Heartlands Hospital, Birmingham, UK

\subsection{6/thoraxjnl-2017-210983.366}

Timings of asthmatic reactions following specific inhalation challenge (SIC) have been defined as immediate, late, dual and prolonged immediate. How they translate into usual workplaces exposure is unknown. We postulated that those with an immediate component would start to react within one hour of regular occupational exposure and start to recover within one hour of leaving work, whereas those with a late reaction would have delayed starting and recovery. Those with dual or prolonged immediate reactions would show early deterioration and delayed recovery. We have compared the timings of reactions in 48 consecutive workers who had positive SIC and had kept serial PEF records at home and with real-world work exposures. These were analysed by the $\mathrm{ABC}$ plot from the Oasys analytical program which combines all measurements done on different work days into 2-hourly blocks and produces plots similar to that seen with SIC, with days away from work as the control exposure. Four experts independently scored the ABC plots to identify workplace deterioration starting at the first timepoint after the start of work, or $\geq 2$ hours later (delayed deterioration), and starting to recover at the first timepoint after leaving work, or $\geq 2$ hours later (delayed recovery). Records with disagreements were resolved in a joint meeting when all records available for an individual worker were compared. The relationship between SIC and real-world exposures is shown in the table. The relationship between laboratory and workplace reactions was only modest, complete concordance in 44\%. Exposures may vary from day to day at work, or that the first reading at work was made before significant exposure has occurred; workers are instructed to make the last reading before work immediate before entering the workplace which should mitigate this. For those with immediate reactions alone during SIC, more showed deterioration in the first workplace reading than showed early recovery after leaving work.

Abstract P224 Table 1 Comparison of timing of asthmatic reactions in the challenge chamber and in real world exposures at work

\begin{tabular}{lllll}
\hline Laboratory challenge reaction & \multicolumn{2}{l}{ Start of deterioration } & \multicolumn{2}{l}{ Start of recovery } \\
\cline { 2 - 5 } & Immediate & Delayed & Immediate & Delayed \\
\hline Immediate $(n=19)$ & 13 & 6 & 9 & 10 \\
Late $(n=10)$ & 4 & 6 & 4 & 6 \\
Dual or prolonged immediate & 10 & 10 & 8 & 12 \\
$(n=20)$ & & & & \\
\end{tabular}

\section{P225 PERSONAL PERCEPTION AND IMPACT OF WORK AGGRAVATED ASTHMA}

${ }^{1}$ LM Bradshaw, ${ }^{1} \mathrm{~J}$ Sumner, ${ }^{2} \mathrm{~J}$ Delic, ${ }^{1} \mathrm{D}$ Fishwick. ${ }^{1}$ Centre for Workplace Health, Buxton, UK; ${ }^{2}$ Health and Safety Executive, Bootle, UK

10.1136/thoraxjnl-2017-210983.367
Workers with asthma frequently complain asthma symptoms are worse at work. Work aggravated asthma (WAA) is asthma made worse by but not caused by workplace exposures. Work practices and exposures can affect asthmatics with mild, moderate or severe asthma.

The aim of this study was to explore the personal perception and impact of WAA. A purposive sampling strategy was used to recruit subjects into this study. The sample was selected from a group of participants in a WAA cross sectional postal questionnaire study. For enrichment qualitative data was also used from the postal questionnaire. All subjects had selfreported WAA and were stratified according to asthma severity. Data were analysed using thematic analysis.

Eighty five subjects provided qualitative data from the postal questionnaire, 6 subjects were interviewed with an in depth face to face interview and one subject an in depth telephone interview. No further interviews were conducted when data saturation point was met. Five main themes concerning the workers perception of WAA were identified. These were; the working environment, lack of understanding about asthma, mental health, social impact and financial impact. Workers believed that a variety of triggers within the workplace caused them to have asthma symptoms. High levels of stress impacted on quality of life and job satisfaction. Some workers were willing to leave the workplace or change career because of the emotional impact feeling stressed at work had on their lives. WAA had an impact on social and family life with individuals giving up socialising when they had asthma symptoms. Feelings of guilt for relying on a partner, children and family to care for them were common. The financial burden of buying inhalers, attending appointments and in some cases reducing working hours or changing to less well paid roles had an impact. There was a perception that employers and colleagues had a lack of understanding of asthma, in particular the variable nature of the disease.

Asthma education programmes in workplaces could help employers and workers understand how to deal with a colleague with asthma and alleviate the stress those workers with WAA experience.

\section{P226 WHAT IS THE LIKELIHOOD OF A DIAGNOSIS OF OCCUPATIONAL LUNG DISEASE WHEN REFERRED TO A SPECIALIST TERTIARY CLINIC?}

JL Hoyle, K Balance. North Manchester General Hospital, Manchester, UK

10.1136/thoraxjnl-2017-210983.368

Background The ratio of patients attending specialist occupational lung disease services who are confirmed to have an occupational lung disease is unknown.

Aim To determine the likelihood of occupational asthma or work related lung disease as a new referral in a specialist tertiary clinic.

Methods Patients seen in a tertiary clinic Jan 2016 to Dec 2016 were identified and case notes examined retrospectively for final diagnosis.

Results 481 patient attendances were identified of which 102 were new referrals. 41 of $102(40 \%)$ were referred as possible work related interstitial lung disease or asbestos related lung disease. 13/41 (31.7\%) were diagnosed asbestosis, 10 (24\%) diffuse pleural thickening, 5 (12\%) pleural plaques, 6 (14.6\%) Usual Interstital Pneumonia (UIP) with asbestos exposure, 3 
(7\%) silicosis, 1 sarcoidosis and 3 unclear. 61 of 102 (60\%) were referred with either possible work related airflow obstruction, asthma like symptoms at work or work related allergy symptoms. 16/61 (26\%) were confirmed as occupational asthma due to a sensitising agent, 10 (16\%) constitutional asthma, 20 (33\%) no lung disease, 1 (1.6\%) smoking related COPD, 5 (8\%) inducible laryngeal obstruction, 2 anxiety, $1(1.6 \%)$ Reactive Airways Dysfunction syndrome, 1 (1.6\%) Byssinosis, 1 (1.6\%) work related anaphylaxis, 1 (1.6\%) work related urticaria. 3 had asthma but the cause remained unclear. 20/61 (33\%) or 1 in 3 cases referred with possible work related airflow obstruction, asthma or allergy had a work related final diagnosis.

Conclusion The majority of cases seen are to determine causes of airflow obstruction/asthma like symptoms rather than interstitial lung disease in the tertiary setting. Most of these are found not to have asthma or a work related diagnosis. More cases of occupational asthma $(16+1$ cases $)$ were identified in total than asbestosis (13 cases); however asbestos related pleural disease was frequently identified (15 cases), making asbestos related disease the most common occupational related lung diagnosis. The likelihood of diagnosing occupational asthma due to a sensitising agent in this tertiary setting is 1 in 4.1 in 3 cases referred with possible interstitial lung disease had sufficient exposure and clinical/radiological evidence for a diagnosis of asbestosis, 1 in 14 (7\%) had silicosis.

\section{P227 A NOVEL CT SCORING SYSTEM DIFFERENTIATES ADMISSIONS SECONDARY TO EOSINOPHILIC FROM NON-EOSINOPHILIC ASTHMA}

${ }^{1} \mathrm{G}$ Hynes, ${ }^{2} \mathrm{M}$ Tsakok, ${ }^{1} \mathrm{R}$ Shrimanker, ${ }^{3} \mathrm{M}$ Bradicich, ${ }^{2} \mathrm{~V}$ St Noble, ${ }^{2} \mathrm{~F}$ Gleeson, ${ }^{1} \mathrm{P}$ Pavord. ${ }^{1}$ University of Oxford, Oxford, UK; ${ }^{2}$ Oxford University Hospitals NHS Foundation Trust, Oxford, UK; ${ }^{3}$ University of Pisa, Pisa, Italy

\subsection{6/thoraxjnl-2017-210983.369}

Introduction Post-mortem studies of patients who have died from asthma show that mucus plugging of the airways is a prominent feature. We have investigated whether this can be identified and quantified on CT scans taken at the time of a severe asthma attack and tested the hypothesis that mucus plugging is specific to attacks associated with a raised blood eosinophil count.

Methods We developed a scoring system based on features on CT scans of asthmatic patients potentially associated with mucus plugging (see Table 1). We used this scoring system to retrospectively score CT scans of 6 patients admitted to the John Radcliffe Hospital, Oxford, with acute attacks of asthma. CT scans were performed within three days of admission to investigate whether there was an alternative cause for the patients' presenting symptoms. Two radiologists, blinded to clinical measures for the patients, independently scored the CT scans.

Results Four patients had a blood eosinophil count $\geq 0.3 \times$ $10^{9} /$ litre at the time of admission. The mean (range) CT score was 18 (17) in these patients and 6 (4) in the non-eosinophilic patients. The intraclass correlation coefficient between the two radiologists' scores was 0.823 . The largest contributors to the difference between the eosinophilic and non- eosinophilic patients' scores was bronchial wall thickening (6 v 1) and mucus plugging ( $3 \mathrm{\vee} 0)$.

Conclusion Our scoring system was repeatable between observers and might potentially identify a pathophysiological mechanism particularly associated with eosinophilic asthma attacks.

Abstract P227 Table 1 CT scoring protocol for patients admitted secondary to asthma. Scans were interpreted by a specialist chest radiologist from slices at three locations on each lung: at the level of the inferior pulmonary vein, at the origin of the lingular bronchus, and at the aortic arch. This gives a score between 0 and 54.

\begin{tabular}{lllll}
\hline & 0 & 1 & 2 & 3 \\
\hline $\begin{array}{l}\text { Bronchial wall } \\
\text { thickening }\end{array}$ & None & Some & Prominent & \\
$\begin{array}{l}\text { Mucus plugging } \\
\text { Mosiacism }\end{array}$ & None & Some & Prominent & \\
Atelectasis & None & Minor & Major & \\
\hline
\end{tabular}

\section{P228 FATTY ACID SUPPLEMENTATION AND ASTHMA: A SYSTEMATIC REVIEW}

WF Kwok, AW Wilson. Norfolk and Norwich Hospital, Norwich, UK

\subsection{6/thoraxjnl-2017-210983.370}

Background Emerging evidence suggests that fatty acid supplementation has a direct effect on the inflammatory cascade, with recently discovered pro-resolving lipid mediators inducing anti-inflammatory mechanisms in animal studies. We aimed to conduct a systematic review to investigate the relationship between omega-3 fatty acid supplementation and respiratory outcomes in adult patients with asthma compared to nonsupplementation.

Methods We identified randomised controlled studies of fatty acid supplementation in adults with asthma through a systematic review of the databases Pubmed, Medline, Embase, CINAHL. Returned Results were screened, quality assessed and cross-checked according to the study inclusion criteria by two researchers.

Results The search found seven high quality studies in the literature suitable for inclusion in the review. Four studies did not show a significant difference in FEV1 between intervention and control groups. Two studies showed an improvement with bronchodilator use, two did not. Three studies showed improvement in Asthma symptoms compared to two studies of no benefit. Two studies showed improvement in peak flow, whereas two did not. Small patient numbers recruited in the studies, differences in fatty acid supplementation at different dosages and lack of published studies limit the strength of evidence presented.

Conclusion There is no significant evidence to suggest supplementation with fatty acids improve pulmonary function in adult patients with Asthma. Evidence for improvement in symptom control is unequivocal. Much of the data is from small short duration studies. Larger studies are required, with non-biologically active control, In the future to evaluate clinical correlation between supplementation and effect on asthma control. 
Abstract P228 Table 1 Summary of studies

\begin{tabular}{|c|c|c|c|c|}
\hline $\begin{array}{l}\text { Study and } \\
\text { population (n) }\end{array}$ & Study Objective & Supplement and dose & Outcome & $\begin{array}{l}\text { Quality } \\
\text { rating }\end{array}$ \\
\hline $\begin{array}{l}\text { Arm et al, } \\
1988 \mathrm{n}=20\end{array}$ & $\begin{array}{l}\text { To test the effect of fish oil supplements on asthma control } \\
\text { and neutrophil function. }\end{array}$ & $\begin{array}{l}10 \text { week, daily supplements containing } 3200 \text { mg EPA } \\
\text { and } 2200 \text { mg DHA compared to control group taking } \\
\text { olive oil capsules (dose not stated). }\end{array}$ & $\begin{array}{l}\text { 1. No significant difference in self-report } \\
\text { symptoms between the two groups. } \\
\text { 2. No significant change in neutrophil } \\
\text { count. }\end{array}$ & Strong \\
\hline $\begin{array}{l}\text { Arm et al, } \\
1989 \mathrm{n}=17\end{array}$ & $\begin{array}{l}\text { To evaluate effect of fish oil supplements on airway response } \\
\text { to allergens. }\end{array}$ & $\begin{array}{l}10 \text { week, daily supplement capsules containing } \\
3200 \mathrm{mg} \text { EPA and } 2200 \mathrm{mg} \text { DHA compared to control } \\
\text { group taking olive oil (dose not stated). }\end{array}$ & $\begin{array}{l}\text { 1. No significant difference in peak flow, } \\
\text { symptom scores or bronchodilator use. } \\
\text { 2. Significantly attenuated late asthmatic } \\
\text { response following allergen challenge after } \\
\text { supplementation. }\end{array}$ & Moderate \\
\hline $\begin{array}{l}\text { Brannan et al, } \\
2015 \mathrm{n}=23\end{array}$ & $\begin{array}{l}\text { Whether Omega-3 fatty acids inhibit airway sensitivity to } \\
\text { inhaled mannitol, a test for bronchial hyper responsiveness. }\end{array}$ & $\begin{array}{l}3 \text { week, daily dose of } \\
400 \mathrm{mg} \text { EPA and } 200 \mathrm{mg} \\
\text { DHA vs control group taking a placebo containing a } \\
\text { blend of omega- } 6 \text { and omega- } 9 \\
\text { Fatty acids. }\end{array}$ & $\begin{array}{l}\text { No difference in FEV1 between } \\
\text { intervention and control group. }\end{array}$ & Strong \\
\hline $\begin{array}{l}\text { Emelyanov et } \\
\text { al, } 2002 \mathrm{n}=46\end{array}$ & $\begin{array}{l}\text { Assess effect of New Zealand Green-lipped mussel } \\
\text { supplement on asthma symptoms and Peak expiratory flow } \\
\text { rate (PEFR) }\end{array}$ & $\begin{array}{l}8 \text { week, daily capsule of lipid extract containing } 50 \mathrm{mg} \\
\text { of polyunsaturated fatty acids EPA and DHA compared } \\
\text { to control taking daily } 150 \mathrm{mg} \text { olive oil capsules. }\end{array}$ & $\begin{array}{l}\text { 1. No difference in mean FEV1 or evening } \\
\text { PEFR. } \\
\text { 2. Mean morning PEFR higher after } \\
\text { supplementation compared to control. } \\
\text { 3. Significant reduction in daytime wheeze } \\
\text { but not bronchodilator use in intervention } \\
\text { group. }\end{array}$ & Strong \\
\hline $\begin{array}{l}\text { Lindermann et } \\
\text { al, } 2009 n=21\end{array}$ & $\begin{array}{l}\text { To evaluate impact of the medical food EFF1009 containing } \\
\text { fatty acids gamma-linolenic acid (GLA), DHA and EPA on } \\
\text { asthma-related quality of life. }\end{array}$ & $\begin{array}{l}4 \text { week, daily meal of EFF1009 containing } 750 \mathrm{mg} \\
\text { GLA, } 500 \text { mg EPA, } 350 \mathrm{mg} \text { DHA compared to control } \\
\text { taking a placebo emulsion contained no } \\
\text { GLA, EPA, or DHA. }\end{array}$ & $\begin{array}{l}\text { 1. No significant difference in FEV1. } \\
\text { 2. Significant improvement in self-reported } \\
\text { asthma symptoms using the Asthma } \\
\text { Control Questionnaire after } \\
\text { supplementation. }\end{array}$ & Strong \\
\hline $\begin{array}{l}\text { Mickleborough } \\
\text { et al, } 2006 \\
\mathrm{n}=16\end{array}$ & $\begin{array}{l}\text { To investigate effect of fish oil supplements on exercise } \\
\text { induced bronchoconstriction (EIB) }\end{array}$ & $\begin{array}{l}3 \text { week, daily dose of fish oil capsules containing } \\
3200 \mathrm{mg} \text { EPA and } 2000 \mathrm{mg} \text { DHA compared to control } \\
\text { taking olive oil capsules (dose not stated). }\end{array}$ & $\begin{array}{l}\text { 1. No significant difference baseline FEV1. } \\
\text { 2. Significant attenuated EIB response } \\
\text { after supplements. } \\
\text { 3. Significant reduction in bronchodilator } \\
\text { use after supplements. }\end{array}$ & Moderate \\
\hline $\begin{array}{l}\text { Mickleborough } \\
\text { et al, } 2013 \\
\mathrm{n}=20 \text {, }\end{array}$ & $\begin{array}{l}\text { Evaluate the effect of New-Zealand green-lipped mussel } \\
\text { supplement (PCSO-524) on airway inflammation and } \\
\text { bronchoconstrictor response to eucapnic voluntary } \\
\text { hyperpnoea (EVH). }\end{array}$ & $\begin{array}{l}3 \text { week, daily dose of PCSO-524 containing } 72 \mathrm{mg} \\
\text { EPA and } 48 \mathrm{mg} \text { DHA compared to control group } \\
\text { taking daily } 150 \mathrm{mg} \text { olive oil capsules. }\end{array}$ & $\begin{array}{l}\text { 1. Bronchodilator use significantly reduced } \\
\text { whilst taking supplement compared to } \\
\text { normal diet or placebo. } \\
\text { 2. Significantly improved mean asthma } \\
\text { symptom scores. } \\
\text { 3. Significantly improved morning and } \\
\text { evening peak flow. }\end{array}$ & Strong \\
\hline
\end{tabular}

EPA: Eicosapentaenoic Acid, DHA=Docosahexaenoic acid, FEV1=Forced Expiratory Flow

Quality Rating adapted from the quality assessment tool for quantitative studies published by the effective public health practice project

\section{P229 A SYSTEMATIC REVIEW OF THE IMPACT OF RHINITIS AND ITS TREATMENT IN SEVERE ASTHMA}

1J Aamir, ${ }^{2} S$ Fowler, ${ }^{3} \mathrm{M}$ Khan. 'Manchester Medical School, Manchester, UK; ${ }^{2}$ Division of Infection, Immunity and Respiratory Medicine, School of Biological Sciences, Faculty of Biology, Medicine and Health, Manchester Academic Health Science Centre, The University of Manchester, Manchester, UK; ${ }^{3}$ University Department of Otolaryngology, Central Manchester University Hospitals, Manchester, UK

\subsection{6/thoraxjnl-2017-210983.371}

Background The unified airway hypothesis proposes rhinitis and asthma are manifestations of a single inflammatory process. However, evidence regarding the association between allergic rhinitis/chronic rhinosinusitis (with or without nasal polyposis) and severe asthma is lacking. This systematic review aimed to identify the relationship between severe asthma and upper airway disease with the objective of understanding of how they are best jointly managed.
Methods We included relevant studies published between 2007 and 2017 in English. Studies were assessed for relevance and quality using predetermined criteria. Two authors independently reviewed the evidence using the GRADE system.

Results Thirteen studies were included; none were randomised controlled trials and five were non-randomised controlled studies. Four themes were identified across the literature: 1. the relationship between allergic rhinitis and severe asthma; 2 . the impact of allergic rhinitis treatment on severe asthma; 3 . the relationship between chronic rhinosinusitis and severe asthma; 4. the impact of chronic rhinosinusitis treatment on severe asthma. Evidence pertaining to each theme was assessed as low quality and Results varied. Three studies demonstrated weak evidence for increased prevalence or severity of allergic rhinitis in severe asthma. One study demonstrated no relationship. Six studies demonstrated weak evidence for the increased prevalence or severity of chronic rhinosinusitis in severe 